Health \& Medicine | Carla Jungquist PhD, ANP-BC, FAAN

\section{Patient safety and opioid medications}

\begin{tabular}{|c|c|c|}
\hline $\begin{array}{l}\text { Hospitalised patients } \\
\text { often require appropriate } \\
\text { pain relief as part of their } \\
\text { treatment. Opioids are } \\
\text { effective medications for } \\
\text { pain management, but can } \\
\text { cause excessive sedation } \\
\text { and respiratory depression } \\
\text { resulting in patient harm. } \\
\text { Dr Carla Jungquist of the } \\
\text { University at Buffalo, School of } \\
\text { Nursing, and a panel of fellow } \\
\text { experts reviewed evidence } \\
\text { from the past decade to } \\
\text { provide an important update } \\
\text { on the prevention of patient } \\
\text { harm when using opioid } \\
\text { medications for acute pain } \\
\text { management. The information } \\
\text { in this article will inform } \\
\text { patients and their loved ones } \\
\text { how to advocate for safe and } \\
\text { effective pain management. }\end{array}$ & $\begin{array}{l}\text { ifty percent of patients that } \\
\text { are hospitalised will receive } \\
\text { opioid medications to control } \\
\text { acute pain. Six out of every } 1000 \\
\text { postoperative patient receiving opioids } \\
\text { will experience a serious adverse event } \\
\text { (Herzig, et al, 2014). One class of } \\
\text { pain relief medication is the opioids, } \\
\text { which include such medications as } \\
\text { codeine, oxycodone, hydrocodone, } \\
\text { buprenorphine, fentanyl, morphine } \\
\text { and methadone. Whilst effective in } \\
\text { relieving pain, opioids can also have } \\
\text { undesired and potentially dangerous } \\
\text { side effects. In 2011, the American } \\
\text { Society for Pain Management Nursing } \\
\text { published guidelines on monitoring } \\
\text { hospitalised patients for opioid-induced } \\
\text { respiratory depression. In 2019, a panel } \\
\text { of f14 experts convened to review } \\
\text { scientifice evidence from the last decade } \\
\text { to provide the following up-to-date } \\
\text { revisions to these guidelines. } \\
\text { OPIOID-INDUCEED RESPIRATORY } \\
\text { DEPRESSION (OIRD) } \\
\text { Patients receiving opioid medication } \\
\text { by any route for pain management } \\
\text { are at risk of opioid-related side } \\
\text { effects. Opioid medications } \\
\text { act on receptors in the } \\
\text { central nervous system to } \\
\text { block the transmission of } \\
\text { pain, and unfortunately also } \\
\text { depress breathing. In usual } \\
\text { circumstances or respiratory } \\
\text { depression, if carbon }\end{array}$ & $\begin{array}{l}\text { oxygen levels falling, the body's } \\
\text { response is to increase respiration to } \\
\text { rectify this. By acting on receptors in the } \\
\text { respiratory centre in the brain, opioids } \\
\text { mute this response, which can lead to a } \\
\text { lack of oxygen getting to the brain and } \\
\text { in turn, brain injury and death. Death } \\
\text { can occur if opioid-induced unintended } \\
\text { advancing sedation (OIUAS) that } \\
\text { advances to opioid-induced respiratory } \\
\text { depression (OIRD) is not quickly } \\
\text { recognised by the healthcare team. } \\
\text { Adverse events from OIRD can occur } \\
\text { in 0.6\% to } 4.2 \% \text { of cases. To manage } \\
\text { this, it is recommended that all } \\
\text { patient and environmental risk factors } \\
\text { should be assessed, quality measures } \\
\text { implemented, opioid-related adverse } \\
\text { eventst tracked, and all members of the } \\
\text { healthcare team be educated on opioid- } \\
\text { related risks to patients. In the event of } \\
\text { life-threatening opioid-induced adverse } \\
\text { events, naloxone (a medication used to } \\
\text { block the respiratory depression effects } \\
\text { of opioids) should be administered at an } \\
\text { appropriate dose. But the best approach } \\
\text { is to avoid excessive respiratory } \\
\text { depression by early recognition using } \\
\text { electronic respiratory monitoring devices } \\
\text { such as continuous pulse oximetry, } \\
\text { capnography or minute ventilation. } \\
\text { INDIVIDUAL PATIIENT } \\
\text { RISK FACTORS } \\
\text { There are certain characteristics and } \\
\text { medical conditions that increase a } \\
\text { patient's risk of developing respiratory } \\
\text { depression from opioid medications. } \\
\text { Higher risk characteristics include } \\
\text { obstructive sleep apnea, obesity } \\
\text { hypoventilation disorder, } \\
\text { undernourished or obese (BMI } \\
\text { less than } 20 \text { or more than } 35) \text {, } \\
\text { impaired kidney, liver, heart, } \\
\text { or lung function, and/or age } \\
\text { greater than } 60 \text { years. }\end{array}$ \\
\hline
\end{tabular}

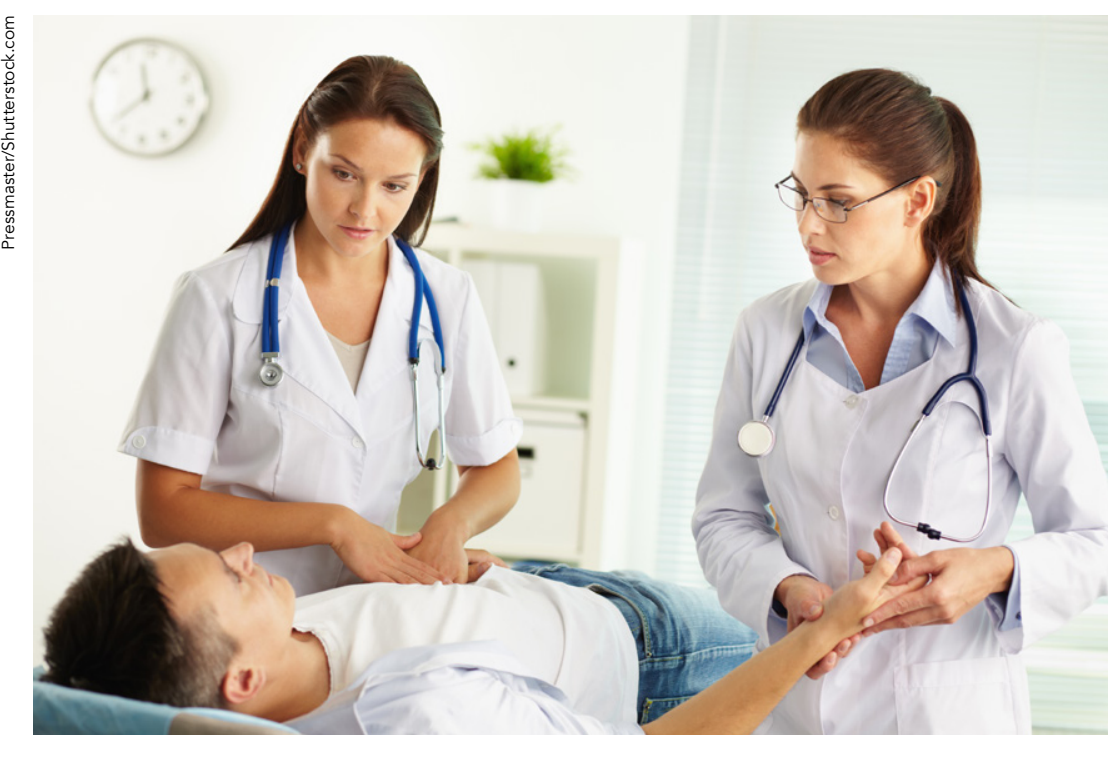

The review of the evidence of opioid medications for acute pain managem
their loved ones how to advocate for safe and effective pain management.

\section{TREATMENT RISK FACTORS} oxygen in the initial 24 hours following surgery. This is recommended for patients with intermittent or constant low oxygen levels after their procedures, but using higher concentrations of oxygen in patients that do not require it may lead to respiratory depression as well as dulling the ability to use pulse oximetry to recognise respiratory depression. Type of anaesthesia used is another factor, patients given a general anaesthetic are at higher risk of OIUAS and OIRD than patients given

HOW TO AVOID PATIENT
HARM - ASSESS AND

COMMUNICATE LEVEL OF RISK

It is the responsibility of the healthcare team to ensure patient safety. Before
starting opioid and other sedating medications, patient's level of risk should be assessed. Risk should be reassessed throughout the patient's treatment Electronic health records (EHRs) could facilitate this by providing a checklist for clinicians to follow during assessment, or by an alert system whenever a patient requires frequent opioid dosing, when other potentially sedative medications are given in addition to opioids, or when anferent form tations of opioids are used (for example, swapping from a
long-acting to a short-acting medication).

Patients should educate themselves on their risk factors and advocate for opioid sparing pain management if they are at high risk.

A patient's plan of care should be based on the individual's level of risk, which may change over their hospitalisation period. Plans should be revised as necessary and communicated between all members of the team caring for the patient. Poor

Opioid drugs act on receptors in the central nervous system to block the transmission of pain.

communication between team members Patient safety can also be improved by communicating the patient's level of risk and monitoring recommendations to the
patient themselves, as well as their family and the healthcare team, especially at shift changeovers.

Patients with obstructive sleep apnoea (a syndrome involving the stopping and starting of breathing whilst asleep, due to throat muscles relaxing and causing obstruction) will be more likely to suffer brain injury or death following opioidrelated respiratory arrest. Use of positive airway pressure therapy (treatment involving a constant how of air to keep the airway open) following anaesthesia can patients with obstrutive seepe evnents with opioids. cause increased se
with opioids.
If OSA has been diagnosed and treated should take their device with them to wear in the hospital or they should ask to use a hospital device. muscle spasms are often treated with benzodiazepines and antihistamines/ antiemetic medications. These classes f medications increase respiratory cautiously with opioid medications.
colitions

\section{HOW TO AVOID PATIENT} HARM - OPIOID SPARING PAIN MANAGEMENT When a patient is found to be at higher isk, opioid sparing pain management strategles should be used. Mall-modal medications and non pharmocon-opioid therapies concurrently with low doseopioid medications to reduce the dose required of each individual component and therefore reduce the risk of

side effects.

inophen is one commonly used sparing pain relief medication, nd has been shown to reduce the opioid equirement during surgery.

Nonsteroidal anti-inflammatory medications are also opioid-sparing, side effects such as increased risk of bleeding and kidney assessed for these rists prio toube.

Anticonvulsant medications (including gabapentin and pregabalin) may cause increased sedation but do reduce the amount of opioid required and are not associated with opioid-induced adverse events.

Antidepressants may be used in the treatment of chronic pain, and may cause increased drowsiness if combined

Clonidine is another drug used to reat pain which may offer opioidsparing effects, although it may also 
Tolerable: Able to perform all permitted activities

Intolerable: Able to perform most permitted activities olerable: pain that becomes intolerable with movement and limits the ability to perform
prescribed physical activities (e.g. out of room ambulation, or physical therapy)

Intolerable: Unable to perform prescribed activities requiring physical exertion. Passive

Intolerable: Unable to perforn
activities* are limited by pain

Intolerable: Unable to do anything or ev
behaviours ( grimacing, moaning, etc.)

-Active activities include walking and activities of daily living. Passive activities include reading, watching $\mathrm{TV}$, and

Patient care plans should be based on the individual's level of risk, which may change over their hospitalisation period.

Ketamine is an anaesthetic medication relief. Evidence exists to support the use of ketamine at low doses to reduce opioid requirements without increasing the risk of respiratory depression. It is ssociated with many side effects even at low doses, incluaing delirium, agitation,

Dexmedetomidine is a sedative drug which reduces opioid requiremen and provides pan relef without depression post-operatively.

Local aesthesia/nerve blocks are often used during procedures and have opioid medication required to contro acute pain.

HOW TO AVOID PATIENT HARM Traditionally, patients are asked to ate their level of pain using a 0-10 pain scale. Over the years, it has been found that using a 0-10 scale increases the likelihood of over medicating the patient. More recent research has shown that using a functional pain scale that assesses the patients' ability to perforn necessany movements and tasks reduces the nisk of overdosing wh functional pain assessment is above. As an example for a hospitalised patie the goal for treatment should be related to tasks such as deep ambulating in the hall, rolling over in bed, attending physical therapy, and/or conversing with visitors.

HOW TO AVOID PATIENT HARM MONITORING RESPIRATORY STAT The nature, timing, frequency and intensity of patient monitoring of breathing should be based on level of risk. Patients should be reassessed throughout their treatment for any response to pain treatments and care plan adjusted accordingly.

Specifically, during the first 24 hours medications, a patient's response to by a nurse before administering an opioid medication, at the time whe the opioid medication is at peak effect and every two hours with intermittent assessments or continuous using nursing assessment should include oxygen saturation, respiratory rate and quality or breath, and level or sedation as well as pain level. The goal for $p$ management shour pain medications should be assessed electronic respiratory monitoring. The this should not be a replacement

for regular assessments by a nurse

Continuous electronic monitoring of

many patients at one time may lead

to alarm fatigue, where members of

staff become desensitised to frequent alerts, rendering them less effective and impacting patient safety.

The type of electronic monitoring used should depend on the patient, for example the presence of supplemental oxygen, their comfort and adherence to the monitoring device, and the capability of the device itself. Devices used include pulse oximetry (to men saturation), the acoustic oxygen saturation), the acoustic
respiratory rate monitor, capnography (to measure carbon di, caphography in the airways when exhaling) the minute ventilation monitor $($ to measure the volume of air inhaled or exhaled per minute). Patients should be monitored for trends (change over time) in variables (such as respiratory rate, sedation level and ventilation parameters from electronic devices) to evaluate improvement, stability or worsening of any values. This can facilitate early detection of OIUAS and OIRD and therefore timely intervention when required.

Hospital policies should ensure that all members of the patient care team are other especilly at shift with each transitions of are, to reduce the risk of opioid related adverse events. Having an appropriate ratio of staff to patients can also increase patient safety. Hourly rounding by nursing staff should include a brief observation of patient safety, breathing, and pain control.

EDUCATION AND POLICIES Clinicians should be educated on best practices for evaluating patient risk for OIUAS and OIRD, assessing sedation level and respiratory status, use of trend monitoring, appropriate use of positive airway pressure therapy, and early interventions if adverse events occur. by developing policies thent safety clinician patient and fmily focus on risks and monitoring procedures.

\section{- Behind the Research} Carla Jungquist, PhD, ANP-BC, FAAN

E: CarlaJun@Buffalo.edu T: +1 716-829-3261 W: http://nursing.buffalo.edu/research/research-highlights.host.html/content/shared/nursing/
esearch-highlights/carla-jungquist.detail.html

\section{Detail}

Carla Jungquist

3435 Main Street, 312 Wende Hal

Buffalo, NY 14214

Bio

Drungquist is an Associate Professor at the University at Center. She has over 30 years of experience in the field of safe and effective pain management, as a bedside RN, Nurse Practitioner, and an academic researcher and

educato

Funding

aty affalo Clinical and Translational Science

Institute

Sentec

Respiratory Motion

- Masimo

Collaborators

ell, PhD, RNC, AH, BC, FAAPM, Private Practice Pain Management Consulting and Education, Wilmington, North Carolina

April Vallerand, PhD, RN, FAAN, Wayne State University, Detroit, Michigan

- Heather L. Carlisle, PhD, DNP, RN-BC, FNP-BC, AGACNP$B C$, University of Arizona, Tucson, Arizona

Westchester Medical

MN, CNS, RN-BC, CCRN, University of Dos Angeles, Los Angeles, California Oakville, Ontario , PhD, University Hospital, Detroit, Michigan Health Sciences Centre, Toronto, Canada - Navdeep Singh, RN, Wayne State University, Detroit, Denise Sullivan, RN, MSN, ANP-BC, ACHPN, NYC Health+ Hospitals/Jacobi, Bronx, New York - Chis Watson, MBA, BSN, RN-BC, East Alabama Center, Opellia, Alabama

D, RN, FAAN, University of

Pensylvani, Philadelphia, Pennsylvania

\section{Research Objectives}

Dr Carla Jungquist's research promotes safe and effective pain management. Specifically, she explores the in

\section{References}

Jungquist, C. et al. (2020) American Society for Pain Managemen Nursing Guidelines on Monitoring for Opioid-Induced Advancing Sedation and Respiratory

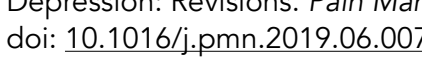
Jungquist, C. et al. (2018) Preventing Opioid-Induced
Respiratory Depression in the Hospitalized Patient With Obstructive Sleep Apnea. Journal of Perianesthesia

\section{Personal Response}

What can patients do to minimise risk of OIUAS and OIRD when being treated with opioid medications?

II 1. Patients and their family should be educated that pain is a necessary protective mechanism and the ability to perform necessary tasks. The goal should never be "no pain". Necessary tasks are ability to breathe, to take deep breaths, to move self in and out of bed or if limited to bed activity only, to be able to re-position self. In cases when the patient is not able to communicate their pain, the nurses will make observations for behaviours or facial expression thought to be pain related. The goal for pain

2. If the patient has been diagnosed with obstructive sleep apnea, they must use CPAP therapy when them or ask the hospital for a loaner device. Make sure the healthcare team has screened them for sleep apnea and applied PAP therapy or instituted opioid sparing pain treatment if they screen positive.

3. The patient or family member should ask the monitored. All patients at higher risk should ask continuously monitored with electronic devices. 